\title{
Legal Aspects on the Harmonization of Albanian Legislation for Industrial Design Protection
}

\author{
Dr. Maksim Qoku \\ Lecturer at the Faculty of Law, University of Tirana \\ maksqoku@gmail.com
}

\section{Doi:10.5901/ajis.2014.v3n6p317}

\begin{abstract}
Based on the analysis and interpretation of the provisions of the Albanian legislation, directives and regulations of the EU, we can say that Albania has succeeded to achieve a good protection of industrial designs, according to the criteria and standards of the EU. Admittedly, the process of integration serves for more interaction and better understanding of the community system, as well as it offers a chance to increase the level of governance, finding the right balance between efficacy and the need for democratic legitimacy. A unified legal regulation at a European level rather than a national one, became so indispensable to guarantee the proper functioning of the internal market, in relation to the products containing designs. This primary interest was accompanied by the one on the investments of European enterprises in the field of more efficient forms of final products compared to the one granted in the past by each state. Thus, the unified European law on designs and models, proposes a special protection technique and increases the value of the products form, as a competitive tool in the market.
\end{abstract}

Keywords: Industrial Design, Community Design, Legal Protection, Procedure, Effects

\section{Introduction}

Until now the EU's activities in the field of intellectual property, has been mainly for the harmonization of national substantive law and the creation of a uniform EU law. This harmonization is achieved on one hand through the designs, models and patents in the field of biotechnological inventions and on certain aspects of copyright and related rights, and on the other hand the EU has created a uniform right, immediately applicable throughout its territory, such as community trademarks, and finally, the community designs and models. The legal regulation of industrial designs and models has been codified in the European legislation on the basis of provisions of TBE and the decisions of the ECJ. Until the unification of the law on industrial designs and models, the legal regulation in the member states was generally different in terms of the object, conditions, duration and thoroughness of the rights recognized by releasing them. The initial harmonization was not sufficient, to expand the freedom of movement of goods in the community, due to the significant differences in national legislations, regarding the object, conditions, duration and scope of the exclusive right. This change caused for commercial enterprises to face the risk that designs and models, which were protected by the law of a member state, not to find protection under the law of another state. This phenomenon brought as a consequence, the legal uncertainty, increasing the legal costs for the protection of these rights, as well as causing the change of the forms of products available in different markets.

\section{Judicial-Legal Source}

There are two main sources at the European level: EC Directive no. 71/1998 of the European Parliament and the Council, dated 13 October 1998 (Directive), and Regulation (EC) no. 6/2002 of the Council, dated 12 December 2001 (Regulation on Community Designs, referred to as R.C.D). The Directive has largely harmonized the material legal regulation of registered design and models law, which have consequences on member states in terms of the object, conditions, scope of protection, and the invalidity of actions that guarantee these rights. The legal regulation of the holder of the right, the registration procedure and the cancellation of the actions that guarantee these rights, has been attributed to the national legislator. Later, through Str. D.K., the unique character of this law and the law itself have been acknowledged throughout the territory of the member states, with the same effect in all the Community. The regulation, except for the criteria provided in the Directive, also provides a uniform regulation regarding the subjective profile, procedure of registration and cancellation of actions which guarantee these rights. The above system includes, on the one hand the national designs 
and models registered in each state, and on the other hand, community designs and models (registered and unregistered), that have consequences on the entire territory of the EU. The law on designs and models is also regulated by community sources, which regulate in general lines, the field of intellectual property (e.g. the Enforcement Directive). Lately, the convents in which the EU has adhered for matters of its competences and which may be called "communitised", are also sources of the community law on designs and models. The present legal framework for the protection of rights deriving from the industrial property in Albania, consists as follows: The Constitution of the Republic of Albania, article 58/1; Law No. 7819, dated 27.04.1994 "On the Industrial Property"; Law No. 8477, dated 22.04.1999 "On some additions and amendments on law no. 7819, dated 27.04.1994 "On the Industrial Property"; Law No. 9947, dated 07.07.2008 "On the Industrial Property"; The Albanian Civil Code approved with law No. 7850, dated 29.07.1994, articles 628-640; The Albanian Criminal Code, articles 148, 149 and 288; The Albanian Civil Procedure Code approved with law No. 8116, dated 29.03.1996, articles 348, 334-336, 208-212, 527-608; The Internal Regulation of ZPM "On Patents, Models for Usage and Industrial Designs".

\section{Conditions and the Right of Protection}

\subsection{Object of protection}

The community harmonization has created a uniform notion of designs and models which are entitled to legal protection. In fact, the international convents mentioned above do not offer a definition of the object of the law on designs; this definition is found in some specific provisions of the Directive and the Regulation, as well as in law no. 9947 dated 07.07.2008 "On Industrial Property" (articles 1, 3.3 and 7 of the Directive; as well as articles 3, 4.2 and 8 of the R.C.D. and article 112.1 of the law). The community sources determine above all, the characteristics of the "aspect" of the product which in principle must be registered as a design or a model. This way: the lines, colors, forms, superficial structure of the products, materials or their decorations, article 1, letter a) of the Directive and article 3 letter a) of the R.C.D. The definition of designs must be coordinated with the expanded definition of the product, which includes "any industrial or handicraft object", including "the packaging, presentations, graphic symbols and topographic letters" (article $1 / b$ of the Directive, article 3/b of R.C.D). The object of the protection is especially broad and includes two or three dimensional forms, which may be applied to an object producible in series (the latter also two or three dimensional) and which influence in its external aspect. It is not required that the protected forms must be presented aesthetically pleasant or to have a useful value. The field of protected forms is restricted by some other provisions, which aim to reduce the protection guarantees in order for the monopolistic effects to be balanced. The first exclusion, is related to the useful forms, also mentioned in the TRIP-s agreement as elements of the form, which are not protected by the law on designs. Article 25 of the TRIP-s agreement, article 7.1 of the Directive, article 8.1 of R.C.D. and article 112.3/a of law no 9947 dated 07.07.2008 "On Industrial Property", provide in general that"...the characteristics of the aspect of a product determined only by its technical function, are not protected by the law on designs and models...". This means that the characteristics of the aspect of a product with technical values may be registered, if the same result achieved by them (the aspect), is possible to be achieved with other forms providing the same function. The second exclusion, is related to the forms that make possible the interoperability among the products. Articles 7.2 of the Directive, 8.2 of the Regulation and article 112.3/b of law no. 9947 dated 07.07.2008 "On Industrial Property", provide that "...there is no protection by the law on designs and models for the characteristics of the aspect of the product which must be necessarily produced in their exact forms and measures are not protected by the law on designs and models, in order for the product in which the design or model has been incorporated, can be joined or linked automatically, with another product in order for each of the products can provide its function...". Conjunctions are not protected as models even when they provide another function other than interoperability, so even when they are substituted with suitable alternative forms (in contract to the elements with a utility value). This exclusion aims to encourage the activity of enterprises which propose replacement or integration parts popular in the market, together with their original products. The third exclusion (Article 3.3 Directive 98/71/Ec Of The European Parliament And Of The Council of 13 October 1998 on the legal protection of designs; article 4.2 Council Regulation (EC) No 6/2002 of 12 December 2001 on Community designs (OJEC NoL3 of 5.1.2002 and article 112.2 of law no.9947 dated 07.07.2008 "On Industrial Properties") regards the registration of parts of a complex product, composed of many components, which can be substituted allowing the dismantling and re-fitting of the product. Two types of such products are distinguished:

a) those composed by a number of specific parts since the beginning and necessary to provide the function for which they have been created; 
b) products that may be composed (or not) and which become complex after the conjunction of two or more independent products: these components may also be traded in a separate way. The Directive and the Regulation provide a unified regulation regarding the registration of parts of complex products, despite the fact that they may pertain to the first or second category. The component of the complex product may be protected only if two conditions are completed, as follows:

1. the visibility during the usage by the final consumer (excluding e.g. the gears and the invisible circles during the usage);

2. the independent presence of the innovation and individuality; for this condition to be completed, the component must have a market value of its own for the user, notwithstanding if it is separated from the value when it is joined with others - the components that are launched are protected despite the need to repair the product in its entirety, which excludes the spare parts from the protection of designs and models.

\subsection{The conditions for protection}

Article 25 of the TRIP-s agreement has regulated for the first time, in an international level, the conditions for the protection of designs and models, by determining that in the member states, the industrial designs that are protected are the ones which are "independently created" and "new or original". Article 3.2 of the Directive, article 4.1 of the Regulation, as well as article 113 of law "On Industrial Property", provides that they shall be "new" and have "individual character", compared to the one which is popular in a certain moment, in order to be competitive in the market. The reference point regarding the timing from which the protection starts:

a) for the designs and models registered in the member states - the date of the filing for registration near the local competent office;

b) for the registered community designs and models - the date of the submission of the request near the Office for the Harmonization of the Internal Market (OHIM), or near one of the national offices for the intellectual property of one of the member states;

c) for the unregistered but protected community designs and models - the date of their launch for the general public (according the relevant forms).

Thus, the criteria for the innovation and individuality are assessed by referring the comparison with designs and models created before the abovementioned dates (the criteria of the priority in time). The Directive and the Regulation have not adopted this version of universal and absolute expansion, in relation to other patents. Regarding the designs, the regulation is more specific, since the element of the priority in time, may only be acquired if performed according to these rules. Both conditions, the innovation and the individuality, must exist simultaneously.

\subsection{The priority in time and innovation}

Article 6, paragraph 1 of the Directive provides that, "...a model is considered 'popular' when it has been published as a result of the registration or in another way, or when it has been used in commerce or has been made public in another way, except for the case when these happenings could not be recognized in a reasonable way, from the specialized environments in the relevant sector acting in the community during the performance of the ordinary commercial activity..." (a similar provision to article 7.1 of R.C.D.). The category of experts is composed by all the professionals of studying, producing and marketing of products which contain designs or models even in only one of the member states. Article 6 of the directive provides three other cases when the design known by third parties, is not considered popular for the general public:

a) when the third person is obliged to save the privacy (article 6.2 of the Directive and 7.1 of R.C.D.);

b) when an abuse has been committed towards the creator of the design or the holder of its right (article 6.3 of the Directive and 7.3 of R.C.D.);

c) when it has been launched by its creator or the holder of the right (...) 12 months before the submission of the request (article 6.2 of the Directive and 7.2 of R.C.D.).

The period of 12 months reserved to the holder of the right, aims to test the trend in the market of the design before its registration, which is meanwhile protected by the community law although it is not yet registered. The moment of the launch for the general public is crucial for the determination of the criteria of innovation and individual character. Article 4.2 of the Directive, 5.2 of the Regulation and article 113 of law "On Industrial Property" provide that, "...designs 
and models are considered identical when their characteristics differ only from 'unimportant' details...". The element of innovation, must bring to an assessment of non-identical, and this assessment is only performed after the first assessment of innovation (the element of time).

\subsection{The individual character}

The Directive provides that the industrial model will be considered individual if the impression it gives to the informed user differs from the overall impression that this user has had from other designs or previous models. The regulation provides one more element, that of the "significant" change of the impression, in comparison with the precedent one: therefore, it is all about a qualified difference.

The doctrine arises a question: who will be considered an informed user: the professional or the ultimate user? In fact, Article 4 of the Directive and Article 6 of the Regulation refer to the informed user, while the figure of the specialist is provided, only in the provisions referring to the criteria of the priority in time. Article 3.4 of the Directive and 4.4 of the Regulation, refer to the customer and ultimate user. Its experience in the field, does not come from theoretical or professional preparation in the field, but stems from the purchase or previous use of the product.

The second problem that arises is about the minimum level of individual character, in order to have protection: a) the difference from the previous design or model must be important or $b$ ) enough that the products are not identical? The difference should be perceptible by the customer. The second problem that arises is about the minimum level of individual character, to enjoy protection: a) change the design or model foregoing, it must be important or b) enough that the products are not identical? The difference should be perceptible by the customer.

\subsection{The allowance}

The designs must complete another condition, in order to be protected: they should be allowed. Article 8 of the Directive and $115 / 1$ of the Law "On Industrial Property" sanction that, "... the model is not protected when it is inconsistent with the public order and good morals (moral norms) ...". The concept of public order and good customs are not unified at a community level, therefore should be created as concepts on the basis of national legal orders when it comes to national designs and models and on the basis of common principles when it comes to community designs and models.

\subsection{Industrial designs created upon request or by an employee}

A design is the result of the creative activity of one or more individuals, but this does not mean that this individual is necessarily also right holder (e.g. the designer is employed). Usually designers exercise their activity during labor relations, or on the basis of the orders of a company that rewards this activity, in order to gain the rights to use the designs. Issues of designs created during labor relations, are addressed by the Regulation. They are not addressed by the Directive, but by the legislations of the member states regarding the determination of the entities that have the right to require registration. However, each state must provide that a model or design cannot be registered, or if it is registered, it will be invalid if the applicant for registration, is not eligible based in the local legislation. The Regulation on the other hand, provides in Article 14, a unified regime regarding titularity, under which the right on a community design or model arises automatically upon its author, but this titularity may be transferred to third parties, against a compensation. In this case, Article 18 of the Regulation provides that, in cases of registered designs and models, the author or authors have the right to have their names mentioned in the registration. Article 14.3 of the Regulation, also resolves potential conflicts between employers and employees, stipulating that if the designs or models "have been created during the employment relationship, they belong to the employer, unless otherwise provided by national legislation." So in this case, the European legislator has provided a unified regime on the basis of which the transfer of ownership from the employee to the employer is not necessary, if the above conditions are met. In fact, these rules do not apply, however, beyond the cases of employment according to law provisions of the member states: in fact, in cases of models or designs created upon request, the regulations on copyright would apply.

\section{The Procedure of the Registration of Designs}

The procedure of registration of the design passes in four stages:

a) The submission of application for the registration of the design; 
b) Examination of formalities;

c) Publication of application;

d) The registration of design.

These stages are the same both in the European Union as well as in Albania. The only difference lies in their rankings. Under Albanian Law No. 9947, dated 07.07.2008, "On Industrial Property", the publication is an earlier stage than the registration, while the EU regulation ( The Council Regulation (EC) No. 6/2002 of 12 December 2001 on Community designs (OJ EC No L 3 of 5.1.2002, p. 1) foresees the inverse.

Based on Article 35 of the regulation, the application may be filed with the Office for the Harmonization of the Internal Market (OHIM), near the central industrial property office of a member state, and for the Benelux countries, near the Benelux Office for Designs. According to the Albanian law, the application is filed at the General Directorate of Patents and Trademarks. The EU application form contains also the obligation to determine the first and the second language, which will be used during the procedures. Currently, the second language may be English, French, German, Spanish and Italian. The application can be completed online via email or via fax.

In the EU, as well as in Albania, two or more designs may be subject to the same application, provided that they belong to the same class, according to the international classification of Locarno. Exceptionally in the EU, the number of designs that may be subject to the same application, shall not exceed 99 designs per application, when it is performed online. The right of priority is regulated in the same way in both legislations. Priority can be claimed only when the application for a Community design is made within six months from the date of filing of the first application in one of the member states of the Paris Convention, or a member state of the World Trade Organization. The effect of the right of priority is that the priority date is calculated as the date of filing of the application for a registered Community design.

The second stage is the examination of the application. The examination is conducted only formally, if all the requirements of the law are met. In the EU regulation, there is no determination on the time when this examination may be performed, while the Albanian law provides that, "... within three months from the date of receipt of application for the registration of a design, the General Directorate of Patents and Trademarks (GDPT), conducts the preliminary examination of the application .. ". When noted that not all the Law/Regulation requirements are met, the applicant is required to complete them within three months from the date of notice under the Albanian law and within a certain time, according to the EU Regulation. The Albanian law gives to the applicant the opportunity to postpone the completion of the deficiencies, with an additional month, while the regulation does not provide for such a thing.

The third stage according to the EU Regulation is the registration, while the Albanian law stipulates the publication of the application as the third stage. The regulation provides that, "... if the requirements that an application for a Community design must meet, are met and the application is not rejected, the Office registers the request in the Register of Community Designs as a registered Community Design ...". The registration will also show the date of filing of the application. After registration, the Office shall publish the registered Community design, in the Community Bulletin of Designs. The registration date shall be the date of filing of the application. The office, thereupon, issues the certificate of registration. This moment constitutes the fourth and last stage, according to the EU Regulation. The same Regulation, also provides for the postponement of the publication, which regards the case when the applicant, in the moment of the filing of the application, asks that the publication of the registered Community design, be postponed for a period of 30 months from the date of filing the application, or if priority is claimed, from the priority date. When there is such a request and the conditions are met, the design will be registered, but neither presentation of the design, nor any folder related to the application, may be open for public inspection. Upon expiry date or earlier with the request of the right holder, the registered community design is published in the Bulletin of Community Designs. If the owner does not pay the publication fee within the deadline, the registered Community design, will not be published and will be considered lost. The right to postpone the publication, is not provided by the Albanian law. According to both legislations, the exclusive right on the design, is obtained upon registration with the relevant office.

Another difference lies in the fact that, according to Albanian law, certain persons may object the published design, within a period of three months from the date of publication although this design has not been registered, as opposed to paying the relevant fee. The examination of the opposition is performed by the Board of Appeals of GDPT and its decision may be appealed in court within 30 days of receiving notice about the decision of the board.

Meanwhile, according to the EU Regulation, only after the design is registered, may a third party request the declaration of its invalidity, through the submission of the complaint near the OHIM. For the initiation of invalidity procedure before OHIM, a person must submit a written request for the declaration of the invalidity. The request must contain specific facts, evidence and demonstrable arguments. It may be submitted by mail, special service distributor, hand delivery by the person himself or by fax, paying a fee of EUR 350 for the request. OHIM does not invested itself in 
finding other evidence, but is limited to the facts and the evidence offered by the parties (DIRECTIVE 98/71/EC OF THE EUROPEAN PARLIAMENT AND OF THE COUNCIL of 13 October 1998 on the legal protection of designs). If the Office finds that the request for the declaration of invalidity is acceptable, the latter shall indicate the grounds of the invalidity. The appeal against the decision of OHIM, may be presented near the Board of Appeal, within two months from the date of notice of the decision and this appeal has a suspensive effect. Once the Board has made a decision, any party affected by it may file a complaint with the Court of Community Designs. Such action shall be performed within a period of two months after the notice of the decision of the Appeals Board.

The court appeal can only be filed because of lack of competence, infringement of an essential procedural requirement, infringement of the Treaty, the violation of this Regulation or any legal right in relation to their application. The Court has jurisdiction to annul or amend the appealed decision. The Albanian law does not regulate the invalidity of the design, it only provides for the repeal and desist from it. The invalidation is mentioned very little in Article 138 ( Law No. 9947, dated 07.07.2008 "On Industrial Property"), which states that, "... the right on the design may be declared invalid even after it has lapsed or been given waived from it ..". Waiving is also stipulated in the EU Regulation.

The waive from a registered Community design shall be submitted in writing near OHIM by the right holder. It will not be effective until recorded in the registry. If a community design, which is subject to the deferment of publication, is waived, it will be considered from the beginning that did not bring the effects specified in this Regulation. A registered design may be waived in part, provided that its form is changed in accordance with the requirements for protection, in order for the identity of the design be preserved as well. Such a regulation is not provided by the Albanian law. Regarding the repeal of the design, the Albanian law provides that the repeal can be performed by the court, upon the request of an interested person, when it does not meet the criteria for protection. A repealed design is impaired from the date of its filing. The decision of the court on the repeal of the design is notified to GDPT, which records it in the register of designs.

\section{The Exercise of Rights}

The applicant, the owner of the registered design, the licensee, the authorized users, or any other person whose rights are violated, have the possibility of the access to the court for these violations. The lawsuit against the violation of rights, must be filed in court within three years from the date the claimant becomes aware of the violation and the violator. The aforementioned persons have the right to address to the court also to demand the banning of other actions in violation of the rights; the removal or blocking of the objects that constitute a violation of civil circulation and if there is no other way, their destruction; the removal or blocking of machines used exclusively for the creation or production of products; the publication of the final court decision in the public media, at the expense of the person who committed the violation. The court decides in each case, the compensation when the violator is liable for damages caused to the plaintiff. ( Article 132 of Law No .9947, dated 7.7.2008 "On Industrial Property")

This provision approaches with Directive 98/71 EC of the EC , which in its Article 12 provides that, " ... upon the registration of a design, its holder has exclusive rights on it and the use by third parties is prohibited ...". (Article 12 of Directive 98/71 EC )The aforementioned use shall include in particular the production, delivery, placing on the market , importing, exporting or using of a product in which the projection is incorporated or to which, such a product has been applied or deposited for the same purposes. The second paragraph of this provision recognizes the abovementioned rights even in the case of an unregistered design, but with the condition that the challenged use is only derived from copying of the protected design.

The court may order that information on the origin and the distribution network of the goods infringing the design, be given or provided by the infringer and / or any other person for whom it the infringement has been deemed on a commercial scale; is has been found to be providing services used in infringing activities on a commercial scale; involvement in the production, manufacture or distribution of goods or the provision of services. Upon request of the party which has presented sufficient evidence to support claims and to base these claims, has other specified evidence, that are in the possession of the opposing party , the court may order that the opposing party submits such evidence provided that the confidential information is protected.

Upon taking early measures, at the request of the person concerned, the court prohibits: the imminent violations or violations that are being incurred; prohibits the entry of goods into the civil circulation, as well as a range of other measures explicitly determined in article 135 of the Law "On Industrial Property".

These measures may be taken by the court without hearing the other party, if they cause irreparable damage to the right holder, or where evidence might be destroyed. The opposing party is immediately notified after the execution of these precautions. The court when deciding on these measures, sets a timeframe when the person who has asked for 
these measures, may file a suit. This period starts from the date of taking of these provisional measures and ends no later than 15 days after this date.

The Directive also provides the restriction for the rights on a Community design. The rights derived from a community design, will not be exercised in respect of acts conducted privately for non-commercial purposes; acts done for experimental purposes, and finally acts of reproduction for the purpose of making quotations or teaching, but with the condition that such acts should be in accordance with fair trade practices.

Our law provides that, if the owner registered designs owner or he holder of the design, represents a appeal-claim for goods imported into the Republic of Albania, or for other goods within the market, which violate its rights, the customs authorities or structures responsible for the market surveillance, are obliged to make the necessary inspection and based on the findings, decide the blocking clearances or their removal from the market, as well as their placement in a safe place. These measures can be removed if the owner of the registered design, or the holder of the design, do not file a lawsuit in court for the violation of rights, for a term within 20 days (working days), from the date of notice of the taking of certain measures by these authorities or structures. ( ${ }^{1}$ Article 136 of Law No .9947 , dated 7.7.2008 "On Industrial Property")

\section{Effects of the Registration of a Design}

\subsection{The rights deriving from the registration}

In order for an industrial design to be legally protected, it must be registered. Our law provides the rights deriving from the registration of an industrial design. The owner of a registered design, has the right to prevent third parties from; producing, importing, exporting, putting on the market, supply, distribute, or keep in custody or possession for these purposes, any product that has this design. The protection of a design shall include any design which does not create a different impression, as a whole, to the informed user (explained in detail above). In assessing the scope of protection, the degree of freedom of the designer in developing the design, should be taken into account.

The rights deriving from the registration of a design shall not be exercised for:

a) acts conducted privately, or for non-commercial purposes;

b) acts conducted for experimental purposes;

c) acts of reproduction for reference or teaching purposes, provided that they are in accordance with fair trade practices, do not unfairly impinge the normal use of the design, as well as mention the origin of the design.

Also, the rights deriving from a registered design, shall not be exercised for:

a) the equipments on ships and aircraft registered in another country when these equipments temporarily enter the territory of the Republic of Albania;

b) the import of spare parts and other accessories, for the repair of these vehicles;

c) repair of these vehicles;

d) the use, of a component part of a complex product, to repair this product so as to restore its original appearance, provided that consumers are duly informed about the origin of this component, to make an informed choice between competing component parts.

The same is provided in the European Directive for the protection of industrial designs, in Articles 12 and 13, while Regulation No. 6/2002 of the European Council, adds a provision on registered and unregistered designs in the Community.

\subsubsection{Effects of a judgment on the right of an unregistered Community design}

An unregistered Community design, however, gives its holder the right to prevent the acts referred to in paragraph 1 , only if the contested use results to have emerged from the protected design. The emerged use, will not be considered as a result of the copying of the protected design if it results from an independent creative work, from a designer who is reasonably thought, to not be familiar with the design made available to the general public by the right holder. ( Council Regulation (EC) No 6/2002 of 12 December 2001 on Community Designs, Article 19)

\subsubsection{Effects of a judgment on the right of a registered Community design}

When there is a complete change of ownership of a registered Community design, as a result of legal proceedings 
contemplated by Regulation 6/2002, licenses and other rights will be extinguished upon registration in the register of the authorized person. If, before the institution of legal proceedings makes the registration, the holder of the registered Community design or the licensee has exploited the design within the Community or made effective and serious preparations to do so, it can still continue the exploitation, provided that its request is made within the period specified by the Regulation, for a non- exclusive license from a new holder, whose name is entered in the register. The license shall be granted for a reasonable period and on reasonable conditions. The preceding paragraph shall not apply if the holder of the registered Community design or the licensee, acted in bad faith at the time when they started to use design, or have made preparations to do so.

The reason given by both types of law is, that a Community design should, as far as possible, serve the needs of all sectors of industry in the Community. Some of these sectors produce a large number of designs for multifunctional products, which have a short life on the market, therefore the protection without the burden of registration formalities is an advantage and the duration of protection is of lesser importance. On the other hand, there are sectors of industry who assess the advantages of the registration for greater legal certainty. This offers and demands at the same time, the possibility of a longer term of protection and which corresponds with a predictable time of the stay of their products in the market.

\subsection{Duration and renewal of the registration}

Based on the legal regulation in Albania, a design registration is valid for 5 years from the date of filing the application for registration. The registration may be renewed at a certain payment, for an additional period of five years, up to a period of 25 years, from the date of filing the application for registration of the design.

Also, the European Community, has provided the same terms for the validity of a design in Article 10 of Directive 98/71 "On the Protection of Industrial Designs"

\subsection{Licensing}

The license contract shall be in writing and signed by the contracting parties, otherwise it is invalid. The contract can be exclusive or non exclusive. The owner of the design may use the rights arising from the registration of the design against the licensee who violates the conditions specified in the contract, during its duration, the form in which it is used, the list and the quality of the products, which the licensee will produce and for which the license has been issued. The license contracts is recorded in the GDPT, in the register of designs, against the payment of a certain fee. The licensee has the right to address the court and perform any other actions provided by law, against the violation of the rights on the design, only with the consent of the licensor, unless when otherwise provide by the license contract provides. When the license is exclusive, the licensee has the right to sue in court and to perform any other actions by law, the violation of the rights over the design, even without the consent of the licensors, if he, although it is informed by the licensee reasonable period. The licensee has the right to intervene in a lawsuit filed by the licensors on infringements of the design rights, when the intervention aims the compensation for the damage suffered by the violation of his rights. ( Article 128 of Law No .9947, dated 7.7.2008 "On Industrial Property")

Whereas for the European Community design may be licensed for the whole or part of the Community. The contract can be exclusive or non-exclusive. The holder of the right of the community design may require the rights derived from the community design, against any licensee who violates any provision of the contract, in the same manner described above for the holder of rights in Albania. Regarding the registration, whereas the license contracts in Albania are registered in the General Directorate of Patents and Trademarks (GDPT), the authority responsible in the European Union, is the Office of Harmonization in the Internal Market (Trade Marks and Designs), referred to as the Office, established by Regulation of the Council (EC) no. 40/94 dated December 20,1993. ( Regulation (EC) No 6/2002 of 12 December 2001 on Community designs, Article 32)

The Office shall maintain a register which will be known as the Register of Community Design, which must contain details on the registration provided under this Regulation, or under the Regulation of implementation. The register is open to public inspection, unless otherwise provided by law.

\subsection{Transfer of the design ownership}

In our law on industrial property, Article 131 , it is provided that "... GDPT registers in the register of designs, at the 
request of the owner of the design, or its new owner, the transfer of ownership of this design, against the relevant payment ...".

The owner of a registered design may transfer its rights on the design, fully or partially, through an agreement signed by both parties, which shall be deposited near the GDPT. The rights on the design, can be transferred along with the business activity or without transferring the latter. The transfer has no legal effect, if not recorded in the register of designs. GDPT refuses the registration in the registry of a required transfer of ownership, if the relevant documentation is not submitted within the deadline.

Regulation 06/2002 of the European Union provides additional provisions to what is mentioned above, specifically in its article 28 , concerning the transfer of a design between different states of the community.

The transfer of a Community design will be possible under the determinations of the following provisions:

(a) at the request of one of the parties, the transfer will enter in the register and get published;

(b) until the time the transfer enters in the register, the successor in title, may not invoke the rights derived from the registration of the Community design;

(c) when there are deadlines to be respected in relation to the Office, the successor in title may perform the corresponding statements near the Office, immediately after the request for the transfer has been accepted by the Office.

The European Community inter alia, has regulated, in Directive 98/71 "On the Protection of Industrial Designs", as well as in Regulation 6/2002 also some other relationships, in terms of the effect that the registration of industrial designs has.

\subsection{The relationship with copyright}

A design protected by a law on designs, registered in a state, or related to a Member State, will also be eligible to protect its legal rights, the law of copyright of that State, from the date on which the design has been created or fixed in any form. The extent and conditions under which such protection has been provided, including the level of the required originality, shall be determined by each Member State.

\section{Conclusion}

Albania needs to undertake a continuous commitment to achieve a similar level of protection of industrial property rights, with the European Union countries. In this context, the discrepancies between the national legislation and the one of the $\mathrm{EU}$, weaken the enforcement of industrial property rights and at the same time cause the fragmentation of the internal market in this field. Precisely for this reason, the objectives of this process remain to be: the undertaking of continuous measures in relation to the improvement of current legislation that governs the industrial property and its full harmonization with the TRIPS Agreement, as well as with the EU Directives in this field; adherence to treaties, conventions and international agreements, in which member countries of the EU have adhered, in order to ensure a higher level, more homogeneous and at the same time, equivalent to the domestic market; establishment of interinstitutional cooperation contacts with counterpart structures of the European Union; drafting of joint programs and participation in joint projects, especially for the training and preparation of specialized people, from all of the above mentioned institutions, on the problems of industrial law. Based on an analysis and interpretation of the provisions of the Albanian legislation with the Directive and the Regulation of the EU, we can say that Albania has already achieved a good and effective protection of industrial designs according to the criteria and standards of the EU. The integration process will serve to more interaction and better understanding of the community system, as well as offering the chance for an increase in the governing level, finding the right balance between the demand for efficacy and democratic legitimacy.

\section{Bibliography}

The work of Ubertazzi L.C, "La propierta inelletuale", Giappicheli, Torino 2011

Law No .9947, dated 7.7.2008 "On Industrial Property"

Council Regulation (EC) No 6/2002 of 12 December, 2001, on Community designs (OJ EC No L 3 of 5.1.2002, p. 1)

Statement on the Approximation of the Draft law with the STRIP-s Agreement and Directives of the EU, prepared by the Office of Patents and Trademarks.

http://oami.europa.eu/ows/rw/pages/RCD/regProcess/invalidity.en.do 
Directive 98/71/Ec Of The European Parliament And Of The Council of 13 October 1998 on the legal protection of designs www.ladas.com/bulletins /design regulation/be

www.wipo.int/madrid/en/forms 